\title{
Newer Oral Anticoagulant Therapy - Prospects and Practices: A Review
}

\author{
Lancy Morries, Niya Mariya, Joel Joby Joseph, Suja Abraham* \\ Department of Pharmacy Practice, Nirmala College of Pharmacy, Muvattupuzha, Kerala, INDIA.
}

\begin{abstract}
The conventionally used anticoagulants for the treatment of thromboembolism include unfractionated heparin, low molecular weight heparin, fondaparinux and Vitamin $\mathrm{K}$ antagonists such as warfarin, phencoumarol. Though they were considered the milestones in anticoagulation therapy, their use in clinical practice is limited due to its certain patient related issues such as wide variations in dose response relationship, delayed onset and offset of action, narrow therapeutic range of clinical effectiveness, frequent monitoring and dose adjustment. In order to overcome the above drawbacks of conventional anticoagulants, FDA approved Newer Oral Anticoagulants that provide stable anticoagulation at a fixed dose without the need for laboratory control, making it more convenient therapeutic regimen. In this review, the use of newer oral anticoagulant drugs in current clinical practice as well as the facts and concerns related to its use, safety and efficacy in patients with concomitant diseases like antiphospholipid syndrome, chronic kidney disease and patients undergoing cardio version is focused. Moreover, the various newer developments and ongoing trials in the field of anticoagulation were also discussed. The emergence of new reversal agents that are currently under development and its role in paediatric populations will be also an added advantage for its development. In short, the use of new anticoagulants had shown improvements in safety and efficacy as well as they offer greatest promise and opportunity for the replacement of Vitamin $\mathrm{K}$ Antagonists and other conventional agents.
\end{abstract}

Key words: Apixaban, Betrixaban, Dabigatran, Edoxaban, Newer oral anticoagulants, Rivaroxaban.

\section{INTRODUCTION}

Venous Thromboembolism, the most common causes of mortality and its rate is about $3 \%$ for patients with deep vein thrombosis (DVT) and 15\% for patients with pulmonary embolism (PE). ${ }^{1}$ According to Centre for Disease Control and Prevention (CDC) statistics, 10 to $30 \%$ people die within one month of diagnosis. ${ }^{2}$ Thromboembolism are 20-45 times more common than atheroembolism, ${ }^{3}$ and the relative risk during pregnancy is much higher. ${ }^{4}$ An epidemiological study showed that the annual incidence of serious complications of DVT is around 60-111 in 100,000 patients in France and 23-107 per 100,000 globally. ${ }^{5}$ However, the incidence of DVT in Indian population is very low as compared to other ethnic groups, since the information available on the incidence is very limited. ${ }^{6}$ In majority cases, the incidence will be clinically silent, since the awareness regarding this life threatening disease is very less. ${ }^{7}$ In about $34 \%$ of young patients presenting with thrombus, a definite cause for thrombophilia predominates. ${ }^{8} \mathrm{~A}$ study conducted by Seema Bhargava showed that hyperhomocystenemia is one of the risk factors in patients with either arterial or venous occlusive disease. ${ }^{9}$ As a result, the Atrial Fibrillation (AF) and valvular disease itself is associated with $76 \%$ of the entire cardiac embolism. ${ }^{3}$

\section{Aim of the review}

This review discusses the prospects and practises of the newer oral anticoagulant therapy in modern medical practises.

\section{MATERIALS AND METHODS}

A detail literature review of newer oral anticoagulants specifically its recent developments and practices in clinical settings was carried out from PubMed using
DOI: 10.5530/ijopp.13.3.35

Address for correspondence: Dr. Suja Abraham, Associate Professor, Department of Pharmacy Practice, Nirmala College of Pharmacy, Muvattupuzha, Kerala, INDIA.

Phone no: +91 9995162188 Email Id: suja@nirmalacp.org

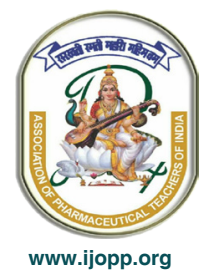


keywords Apixaban, Betrixaban, Dabigatran, Edoxaban, Newer oral anticoagulants, Rivaroxaban.

\section{EVOLUTION OF ANTICOAGULANTS}

Unfractionated heparin (UFH), Low Molecular Weight Heparin (LMWH), Fondaparinux and Vitamin K antagonists (VKAs) were considered the milestones in anticoagulation therapy. ${ }^{10}$ Though, the evidence from various trials showed that, even among elderly AF patients who are at high risk, the use of VKAs reduce the risk of stroke by about one-thirds. ${ }^{11}$ The practical limitations such as wide variations in dose response relationship, delayed onset and offset of action and dose adjustment ${ }^{10,12}$ of traditional drugs fuelled the search for newer anticoagulants. A large phase III clinical trial showed that, these Novel drugs provide stable anticoagulation at a fixed dose without any need for laboratory control. ${ }^{13,14}$

Newer Oral Anticoagulants (NOACs) otherwise referred as Target Specific Oral Anticoagulants or Non-vitamin-Koral Anticoagulants, that specifically and selectively block the central elements of coagulation cascade. ${ }^{15}$ They have been introduced into market with the aim to optimize and simplify the anticoagulation therapy by improving patient experience and reduce the need for dietary restrictions and routine anticoagulation monitoring thus satisfying the individual needs of the patients. Moreover, they can produce a predictable and less labile anticoagulant effect. ${ }^{16}$ Recently FDA approved two new classes of orally administered anticoagulants, namely Direct thrombin inhibitors and Factor Xa inhibitors, ${ }^{17}$ that inhibit a single activated clotting factor. ${ }^{18}$ The introduction of NOACs, remarkably changed the perspective in the management of venous and arterial thromboembolic diseases. ${ }^{19}$

\section{ANTICOAGULANTS IN CURRENT PRACTICES}

The first FDA approved drug was UFH in 1940, ${ }^{20}$ followed by warfarin in the year $1950 .{ }^{10}$ Clinical trials indicated, a weight adjusted dosing regimen of UFH can provide more predictable anticoagulation than a fixed initial dose, particularly for patients with Non ST elevated-Acute Coronary Syndrome. ${ }^{21}$ Later in 1980, the LMWH was approved and clinical data showed that its use can significantly improve the overall survival of cancer patients by its direct effect on the metastasis. ${ }^{3}$ In early $20^{\text {th }}$ century, a synthetic analogue of antithrombin was approved (Fondaparinux), but its use was contraindicated in patients with $\mathrm{CrCl}$ less than $30 \mathrm{ml} / \mathrm{min} .{ }^{22}$ Even after the development and application of these drugs, the treatment and prevention of thrombotic diseases remains a major medical challenge. ${ }^{23}$ With the introduction of
NOACs, major limitations of warfarin were resolved. Newer agents provides immediate anticoagulant effect (time to peak effect ranges from $1-4 \mathrm{hr}$ ), ${ }^{24}$ but at the same time due to the shorter half-life, missed doses may result in greater risk of thromboembolic complications.

Due to certain concerns regarding the use of NOACs including medication adherence without laboratory monitoring, uncertainty about dosing in patients with renal dysfunction or extremities of body weight, the entry of this new therapeutic regimen into clinical practice takes much time. ${ }^{25}$ Therefore clinical evaluation initially begins with short term indications such as prophylactic therapy for VTE who undergone orthopaedic surgery, followed by evaluation in chronic conditions such as stroke prevention in $\mathrm{AF}^{26}$ Within few years after clinical evaluation, the use of Newer drugs has been increased dramatically. Currently, they are used for the treatment and prevention of DVT and PE,,$^{27-30}$ stroke and systemic embolisms in Non-Valvular Atrial Fibrillation (NVAF) with at least one additional risk factor ${ }^{31-34}$ including age $\geq 65$ years, presence of heart failure, vascular disease, hypertension and diabetes mellitus; ${ }^{35}$ primary prevention of venous thromboembolic events in patients who have undergone elective hip/ knee replacement surgery. ${ }^{36-38}$

However, the use of Newer drugs is contraindicated particularly in patients with significant liver failure ${ }^{39}$ or hepatic insufficiency with Child-Pugh category $\mathrm{C},{ }^{40}$ moderate to severe renal failure $(\mathrm{CrCl}$ less than $30 \mathrm{ml} / \mathrm{min}$ ), organ lesion at risk of bleeding including intracranial hemorrhage, spinal or epidural-catheter in previous six months and pregnancy or lactation. In patients with AF using mechanical prosthetic valve or moderate-severe mitral stenosis of rheumatic origin, (except in bio-prosthetic valve, mitral valve repair or transcatheter aortic valve replacement) the use of Newer drugs are considerable, though the available data are limited. $^{22}$

\section{ORAL ANTICOAGULANTS: - NEWER DEVELOPMENTS}

Based on results from Randomised Control Trials ${ }^{41}$ including more than 50,000 patients all over world, FDA approved Dabigatran, Rivaroxaban, Apixaban inferring that they are either equivalent or more effective to warfarin in preventing stroke with acceptable bleeding risk. ${ }^{42}$ Dabigatran, the first oral direct thrombin inhibitor approved by FDA in 2010 for the prevention of stroke in NVAF as well as for the prophylaxis and treatment of VTE. ${ }^{43}$ In certain regions a reduced dose of $110 \mathrm{mg}$ is recommended, in moderate renal impairment $(\mathrm{CrCl}$ $30-50 \mathrm{ml} / \mathrm{min}$ ) and geriatric groups who are at high risk of bleeding or those treated with Verapamil. ${ }^{11}$ Since 
$80 \%$ drug is excreted renally, in severe renal failure, the recommended dose is $75 \mathrm{mg}$ twice daily. ${ }^{44}$ The Randomised Evaluation Of Long Term Anticoagulation Therapy (RE-LY) Trial showed that, the administration of $150 \mathrm{mg}$ twice daily reduce the risk of stroke and other systemic embolism when compared with $110 \mathrm{mg}$ dose, ${ }^{13}$ but at the same time increased the rate of bleeding risk in 150mg group. ${ }^{45,46}$ The main advantage of Dabigatran over other indirect thrombin inhibitors is its reversible binding that provide more prognostic anticoagulant therapy and was found to be safer. ${ }^{47}$ However, a case report from 80 year old patient who recently started the drug for new onset AF, presented with Acute Kidney Injury, haematuria and RBC casts in the urine specimen and was diagnosed with Drug Induced Anticoagulant Nephropathy. ${ }^{48}$

In 2011, the first oral Factor Xa inhibitor, Rivaroxaban was approved. A study showed that both Dabigatran and Rivaroxaban have stable pharmacodynamics profile making them a suitable alternative for Warfarin. ${ }^{49}$ The COMPASS (phase III) ${ }^{50}$ study showed that Rivaroxaban $2.5 \mathrm{mg}$ twice daily plus Aspirin $100 \mathrm{mg}$, compared to Aspirin alone, ${ }^{51}$ and Rivaroxaban alone (reduce major adverse limb events and increase major bleeding) ${ }^{52}$ can significantly reduce the occurrence of major adverse limb events (MALE) in people with peripheral arterial disease (PAD). Based on this study, the application for the approval of new vascular indications have been submitted for reducing the risk of major cardiovascular events including cardiovascular death, heart attack or stroke in patients with chronic coronary artery disease and/or PAD as well as reducing the risk of acute limb ischemia in patients with PAD ${ }^{51}$ But the limited evidence available showed that, the occurrence of miscarriages and rate of anomalies are higher, that may raise the concerns regarding the safety of embryo-foetal issues with its use. ${ }^{53}$ Moreover, it produces a significantly higher risk of haemorrhagic stroke or hematoma with a lower risk of subdural hematoma than those taking Dabigatran, ${ }^{46}$ and also increases the rate of major bleeding unrelated to coronary artery bypass graft. ${ }^{54}$

In 2012, Apixaban (a factor Xa inhibitor) was approved by the FDA. It was the only drug that cause a substantial reduction in overall bleeding from any cause ${ }^{41}$ especially when compared to Rivaroxaban, ${ }^{55}$ which is associated with higher risk of major bleeding. ${ }^{56,57}$ On other hand, Apixaban has an equal overall bleeding rate when compared to warfarin. ${ }^{55}$ The dose will be halved $(2.5 \mathrm{mg})$ if patient shows two or more of the following characteristics-age above 80years, weight less than or equal to $60 \mathrm{~kg}$ or if Creatinine greater than or equal to $1.5 \mathrm{mg} / \mathrm{dl}{ }^{43,44,58}$ Two clinical trials associated with
Apixaban in paediatric population is on-going, one is regarding the safety and pharmacokinetics of Apixaban in patients with Congenital or Acquired Heart Disease (phase 2 trial); ${ }^{59}$ second is to evaluate single dose of Apixaban in paediatric subjects at risk for thrombotic disorder. ${ }^{60}$

In 2015, Edoxaban (Factor Xa inhibitor) was approved for reducing the risk of stroke and systemic embolism in patients with NVAF, which is available in $60 \mathrm{mg}$ and $30 \mathrm{mg} .{ }^{61}$ Phase II dose finding study demonstrated that once daily regimen have more safety profile than twice daily regimen in terms of bleeding incidence when compared to Warfarin. ${ }^{62}$ But the safety and total clinical benefit of higher dose regimens across the range of renal function are consistent due to its reduced efficacy in preventing arterial thromboembolism in the upper range of $\mathrm{CrCl}^{63}$ A Hokusai study comparing the efficacy of Edoxaban versus standard of care in paediatric patients with confirmed VTE, PE and DVT is an on-going trial in US. ${ }^{64}$

In 2017, Betrixaban (direct Factor Xa inhibitor) was approved for the prophylaxis of VTE in adult patients hospitalized for an acute medical illness who are at risk for thromboembolic complications. ${ }^{65}$ Its unique pharmacokinetic characteristics including limited renal excretion, minimal metabolism through the CYP450 enzymes and a longer half-life, made this drug suitable in patients with poor renal function. ${ }^{66} \mathrm{It}$ is safe and effective as Enoxaparin and Warfarin at a dose of $30-80 \mathrm{mg}$ for prevention of stroke in AF patients. ${ }^{67}$

\section{NEWER ANTICOAGULANTS: FACTS AND CONCERNS}

A meta-analysis of phase III trial, conducted by Ruff et al. on 2013 compared the safety and efficacy of NOAC with Warfarin and demonstrated that NOACs cause a reduction in haemorrhagic stroke by $51 \%$, all-cause mortality by $10 \%$ and intracranial haemorrhage by $52 \%,{ }^{68}$ but can increase the complications of gastrointestinal bleeding by $25 \%$.

When the patient is on chronic use of NOAC, a structured follow-up including the documentation of anticoagulation indication and monitoring of baseline laboratory parameters like haemoglobin, renal and liver function are recommended. The shorter course of antiplatelet is recommended when single or dual antiplatelet therapy is combined with NOACs. Exceptions include patient with elective percutaneous coronary intervention (PCI), who may benefit from dual therapy (NOAC plus clopidogrel from discharge through one year). However, if a patient taking NOAC immediately experience an acute ischemic stroke, then they can proceed with thrombolysis, only if 
the plasma level is just below the lower limit of detection or if the last administration was before $48 \mathrm{hr}$ in those with normal renal function. In such patients the reinitiation should be considered only after 3-14 days, based on the degree of neurological deficit. Almost all NOAC are renally excreted, for appropriate dosing, it is important to calculate the renal function using the Cockcroft Gault equation. ${ }^{40}$ If the $\mathrm{Crcl}$ less than $15-30 \mathrm{ml} / \mathrm{min}$ or if the patient is on dialysis, the use is not recommended except Apixaban whose use is moderately effective in dialysis patients. ${ }^{44}$

The USFDA approved the first specific reversal agent Idarucizumab $(5 \mathrm{mg}$ IV in 2 doses no more than $15 \mathrm{~min}$ apart) which is a fully humanised antibody fragment for dabigatran in October 2015. ${ }^{69}$ Based on the result of the phase III RE-VERSE AD trial, ${ }^{65}$ it was found that the instant reversal of anticoagulant effect has no adverse events related to the safety and has a lower rate for thrombotic events.

In 2018, USFDA approved the first anti-factor Xa inhibitor ANDEXANET ALFA (ANDEXXA). Studies about this intravenous drug are still under regulatory review in European Union and under clinical development in Japan. ${ }^{70}$ It were indicated mainly for the reversal of anticoagulation due to life threatening or uncontrolled bleeding in patients treated with Rivaroxaban and Apixaban. ${ }^{71}$ But it has not shown effective for the treatment of bleeding related to any other Factor Xa inhibitors. However, its post marketing surveillance study was initiated in $2019^{65-71}$ with the findings presented in $2023 .{ }^{72}$

\section{NOACS IN PATIENTS WITH CONCOMITANT DISEASE}

CKD patients experience an increased risk of ischemic stroke, gastro intestinal bleeding events and decreased risk of intracranial bleeding with the use of NOAC. When compared with VKAs, the risk of mortality was slightly more. This should be used with caution in elderly patients, as they have moderate-severe renal insufficiency. Moreover, the recommended doses of newer drugs are non-inferior and comparatively safe in those patients when compared with conventional anticoagulants. ${ }^{73}$

X-VeRT (eXplore the efficacy and safety of once daily oral riVaroxaban for the prevention of cardiovascular events in patients with NV a Trial fibrillation scheduled for cardio version) was the first randomised trial of NOAC in patients with NVAF undergoing elective cardio version. The study found that, Rivaroxaban when compared with VKA therapy, was associated with similar rate of stroke or other cardiovascular events and bleeding but significantly a shorter time to cardioversion. ${ }^{58}$
Antiphospholipid Syndrome, a condition which is characterized by the occurrence of thromboembolic events or pregnancy loss combined with at least one laboratory criteria among lupus anticoagulant (LAC), anti-cardiolipin (aCL) and anti-beta 2 glycoprotein (aß2 GP1) antibodies. The primary therapy for this condition is anticoagulation with VKA being the standard drug of choice. ${ }^{74}$ However, NOACs would simply the treatment, but its efficacy is not verified. ${ }^{75}$

These novel agents can be used in patients with moderate liver insufficiency, though dose adjustments are required. However, the use of Apixaban and Rivaroxaban in hepatic disease is contraindicated especially in ChildPugh category $\mathrm{B}$ and is associated with clinically relevant risks and coagulopathy. In mild or moderate hepatic impairment, Apixaban can be administered with extreme caution. ${ }^{76}$

\section{ONGOING TRIALS FOR BETTER OPTIONS}

Ionsis and Bayer from Global data are developing a drug "IONIS- FXIRX", a second generation antisense anticoagulant which is currently under phase II clinical trial. The major advantage of this drug is that, it separates the antithrombotic activity from bleeding risk. The currently available data shows that, it is expected to launch by $2022 .{ }^{77}$

A novel VKA, “Tecarfarin”, developed by Espero and Armetheon, is under phase III clinical trial for treating the patients with prosthetic heart valve and renal insufficiency, is expected to launch by $2023 .{ }^{.7}$ "Idrabiotaparinux" the another compound which is under phase III clinical trial (international, multicentre, randomized, doubleblind, double-dummy parallel study) for the prevention of recurrent VTE in patients with acute PE. Once it is approved, it will be the first once weekly anticoagulant

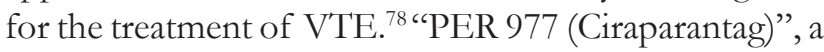
small water soluble molecule that will act as a nonspecific reversal agent. ${ }^{69}$ The phase I/II trial showed that, it will reverse the anticoagulant activity of Enoxaparin 100mg and $200 \mathrm{mg}$ IV dose within $20 \mathrm{~min}$ and 5 min respectively using Whole blood clotting time. The phase II trials with Ciraparantag are ongoing. ${ }^{79}$

However, certain anticoagulant drugs were discontinued from clinical trial during the manufacturing process, including "SSR-126517, a biotinylated idraparinex" which had been in phase III clinical trial at Sanoffi for the treatment of PE, DVT and AF was discontinued in 2009. ${ }^{78}$ The "Semuloparin Sodium" (LMWH) for the primary prophylaxis of VTE in cancer patients receiving chemotherapy for locally-advanced or metastatic solid tumors was discontinued due to its higher bleeding related 
events. "Darexabam Maleate," (oral direct thrombin inhibitor) developed by Astellas Pharma, was discontinued from the global development since it cannot find a phase III development partner. ${ }^{81}$

\section{CONCLUSION}

The development and introduction of NOACs into market had brought an exclusive advancement in the field of anticoagulation. Since, they have maximum efficacy with least adverse effects, they are considered as the promising drugs. Unlike other anticoagulants, they do not require regular monitoring, thus making them more patient friendly. Once weekly regimen can be considered as an emerging area in the field of research and can improve patient adherence. The emergence of new reversal agents will definitely change the entire face of NOACs. In addition to that, the role of anticoagulants in paediatric populations will be also an added advantage for its development. In short, the convenient use of new anticoagulants had shown improvement in safety and efficacy as well as they offers the greatest promise and opportunity for the replacement of VKA. ${ }^{47}$ Thus the development of newer agents for special population still is a topic of interest for the future.

\section{ACKNOWLEDGEMENT}

We thank the Almighty for helping us to complete this work.

\section{CONFLICT OF INTEREST}

The authors declare no conflict of interest.

\section{ABBREVIATIONS}

CDC: Centre for Disease Control and Prevention; DVT: deep vein thrombosis; AF: Atrial Fibrillation; UFH: Unfractionated heparin; LMWH: Low Molecular Weight Heparin; VKAs: Vitamin K antagonists; NOACs: Newer Oral Anticoagulants; NVAF: Non-valvular atrial fibrillation.

\section{REFERENCES}

1. Andrade AR, Barros LL, Azevedo MFC, Carlos AS, Daimio AOMC, Sipahi AM, et al. Risk of thrombosis and mortality in inflammatory bowel disease. Clin TransI Gastroenterol. 2018;9:142

2. Beckman MG, Hooper WC, Critchley SE, Ortel TL. Venous Thromboembolism: A public health concern. Am J Prev Med, 2010;38(4 Suppl):S495-501.

3. Dag O, Kaygin D, Erkect BK. Analysis of risk factors for amputation in 822 cases with acute arterial emboli. Scientific World Journal. 2012;(6):673483.

4. Heit JA, Catie E, Andra HJ, Petterson MT, Bailey RK, Melton J. Trends in the Incidence of Venous Thromboembolism during Pregnancy or Postpartum: A 30Year Population-Based Study.Ann Intern Med. 2005;143(10):697-706.

5. Bénard E, Lafuma A, Ravaud P. Epidemiology of venous thromboembolic disease. Presse Med. 2005;34(6):415-9.

Indian Journal of Pharmacy Practice, Vol 13, Issue 3, Jul-Sep, 2020
6. Bagaria V, Modi N, Panghate A, Vaidya S. Incidence and risk factors for development of venous thromboembnolism in Indian patients undergoing major orthopaedic surgery: Results of a prospective study. Postgrad Med J. 2006;82(964):136-9.

7. Agarwal S, Dhas A, Sanghi R, Stephen E. Venous thromboembolism: A problem in the Indian/ Asian population. Indian J Urol. 2009;25(1):11-6.

8. Ghosh K, Shetty S, Madkaikar M, Pawar A, Nair S, Khare A, et al. Venous thromboembolism in young patients from western India: A study. Clin Appl Thrombosis/Hemostasis. 2001;7(2):158-65.

9. Bhargava S, Parakh R, Manocha A, Ali A, Srivastava LM. Prevalence of Hyperhomocysteinemia in Vascular Disease: Comparative Study of Thrombotic Venous Disease versus Occlusive Arterial Disease. Vascular. 2007;15(3):14953.

10. Franchini M, Liumbruno MG, Bonfanti C, Lippi G. The evolution of anticoagulant therapy. Blood Transfus. 2016;14(2):175-84.

11. Huisman VM, Lip GYH, Diener HC, Brueckmann M, Ryn J, Clemens A. Dabigatranetexilate for stroke prevention in patients with atrial fibrillation: Resolving uncertainties in routine practice. Thromb Haemost. 2012;107(05):83847.

12. Harel Z, Sholzberg M, Shah P, Pavenski K, Harel S, Wald R, et al. Comparison between NOACs and VKAs in patient with Chronic kidney disease. J Am Soc Nephrol. 2014;25(3):431-42.

13. Connolly SJ, Ezekowitz MB, Salim Y, Eikelboom J, Oldgren J, Parekh A, et al. Dabigatran versus Warfarin 6in patients with atrial fibrillation. $\mathrm{N}$ Engl $\mathrm{J}$ Med. 2009;361(12):1139-51.

14. Granger CB, Alexander JH, Murray JJ, Lopes RD, Hylek EM, Hanna M, et al. Apixaban versus Warfarin in patients with atrial fibrillation. $\mathrm{N}$ Eng $\mathrm{J}$ Med. 2011;365:981-92.

15. Steffel J, Lüscher TF. Novel anticoagulants in clinical development: Focus on factor Xa and direct thrombin inhibitors. J Cardiovasc Med. 2009;10(8):616-23.

16. Hicks $T$, Stewart F, Eisinga A. NOACs versus warfarin for stroke prevention in patients with AF: A systematic review and meta-analysis. Open Heart. 2015;3(1):1136-48.

17. Mantha S, Ansell J. An indirect comparison of dabigatran, Rivaroxaban and apixaban for atrial fibrillation. Thromb Haemost. 2012;108:476-84.

18. Gopalakrishnan S, Srinivasan N. Oral anticoagulants: Current Indian scenario. 2013. Available from: www.apiindia.org/medicine_update_2013/chap90.pdf

19. Palladino M, Merli G, Thomson L. Evaluation of the oral direct factor Xa inhibitorBetrixaban. Expert Opin Investig Drugs. 2013;22(11):1465-7.

20. Harter K, Levine M, Henderson OS. Anticoagulation Drug Therapy: A Review. West J Emerg Med. 2015;16(1):11-7.

21. Amsterdam AE, Wenger NK, Brindis RG, JrCasey DE, Ganiats TG, JrHolmes DR, et al. 2014 AHA/ACC Guideline for the Management of Patients with NonST-Elevation Acute Coronary Syndromes: A report of the American College of Cardiology/American Heart Association Task Force on Practice Guidelines. J Am Coll Cardiol. 2014;64(24):e139-228.

22. National Institute for Health and Care Excellence (NICE). Rivaroxaban for preventing adverse outcomes after acute management of acute coronary syndrome. Technology Appraisal Guidance [TA335]. 2015. Available from: http://guidance.nice.org.uk/TA335

23. Mckaj YH, Mckaj YA, Ermira I, Duci SB. New oral anticoagulants: Their advantages and disadvantages compared with Vitamin K Antagonists in the prevention and treatment of patient with thromboembolic event. Ther Clin Risk Manag. 2015;(11):967-77.

24. Cheung J. Prescriber Decision Support: Novel or non-vitamin k antagonist oral anticoagulants (NOAC). Medicines Optimisation Team, GMMMG NHS. 2015. Available from: gmmmg.nhs.uk/docs/.../151124-NOAC-prescriber-decisionNovember-2015-v2-0.pd.

25. Olson H. Advantages and Disadvantages of Novel Oral Anticoagulants. Rockford: Diagnostic and Interventional Cardiology. 2016. Available from: https://www.dicardiology.com/.../advantages-and-disadvantages-novel-oralanticoagul.

26. Halperin, Jonathan L. What can ongoing clinical trials of anticoagulants demonstrate?. J Cardiovasc Med. 2009;10(8):610-5.

27. National Institute for Health and Care Excellence (NICE). Dabigatranetexilate for the treatment and secondary prevention of deep vein thrombosis and/or pulmonary embolism. Technology appraisal guidance [TA327], 2014; Available from: https://www.nice.org.uk/guidance/TA327/chapter/1-Guidance

28. National Institute for Health and Care Excellence (NICE). Rivaroxaban for treating pulmonary embolism and preventing recurrent venous thromboembolism. 
Technology appraisal guidance [TA287], 2013; Available from:https://www.nice. org.uk/guidance/ta287

29. National Institute for Health and Care Excellence (NICE). Apixaban for the treatment and secondary prevention of deep vein thrombosis and/or pulmonary embolism. Technology appraisal guidance [TA341]. 2015. Available from: https://www.nice.org.uk/guidance/ta341/../deep-vein-thrombosis-pulmonaryembolis.

30. National Institute for Health and Care Excellence (NICE). Edoxaban for treating and for preventing deep vein thrombosis and pulmonary embolism. Technology appraisal guidance [TA354], 2015. Available from:https://www.nice.org.uk/ guidance/ta354

31. National Institute for Health and Care Excellence (NICE). Dabigatranetexilate for the prevention of stroke and systemic embolism in atrial fibrillation. Technology appraisal guidance [TA249]. 2012. Available from:https://www.nice. org.uk/guidance/ta249/evidence

32. National Institute for Health and Care Excellence (NICE). Rivaroxaban for the prevention of stroke and systemic embolism in people with atrial fibrillation Technology appraisal guidance [TA256]. 2012. Available from:https://www.nice. org.uk/guidance/ta256/chapter/6-related-nice-guidance

33. National Institute for Health and Care Excellence (NICE). Apixaban for preventing stroke and systemic embolism in people with nonvalvular atrial fibrillation Technology appraisal guidance [TA275]. 2013. Available from: https:// www.nice.org.uk/guidance/ta275/.../stroke-and-systemic-embolism prevention-

34. National Institute for Health and Care Excellence (NICE). Edoxaban for preventing stroke and systemic embolism in people with non-valvular atrial fibrillation Technology appraisal guidance [TA355]. 2015. Available from: https://www.nice.org.uk/guidance/ta355

35. Olesen JB, Fauchier L, Lane D, Taillander S, Lip GYH. Risk factors for stroke and thromboembolism in relation to age among patients with atrial fibrillation. Chest. 2012;141(1):147-53.

36. National Institute for Health and Care Excellence (NICE). Dabigatranetexilate for the prevention of venous thromboembolism after hip or knee replacement surgery in adults Technology appraisal guidance [TA157]. 2008. Available from: https://www.nice.org.uk/guidance/ta157/.../dabigatran-etexilate-for-theprevention-of-

37. National Institute for Health and Care Excellence (NICE). Rivaroxaban for the prevention of venous thromboembolism after total hip or total knee replacement in adults Technology appraisal guidance [TA170]. 2009. Available from: https:// www.nice.org.uk/guidance/TA170

38. National Institute for Health and Care Excellence (NICE). Apixaban for the prevention of venous thromboembolism after total hip or knee replacement in adults Technology appraisal guidance [TA245]. 2012. Available from:https:// www.nice./org.uk/guidance/ta245

39. Emergency Care Institute, New South Wales: Agency for Clinical Innovation. 2014. http://www.aci.health.nsw.gov.acc

40. Steffel J, Verhamme P, Potpara TS, Albaladejo P, Antz M, Desteghe L, et al. 2018 EHRA Practical Guide to NOAC Use in AF. Eur Heart J. 2018;39(16):1330-93.

41. Loo SY, Coulombe J, DellAniello S, Brophy JM, Suissa S, Renoux C. Comparative effectiveness of novel oral anticoagulants in UK patients with nonvalvular atrial fibrillation and chronic kidney disease: A matched cohort study. BMJ Open. 2018;8(1):e019638.

42. Unger EF. Atrial fibrillation and new oral anticoagulant drugs. USFDA. 2015. Available from: https://www.fda.gov/drugs/newsevents/ucm405148.htm

43. Joppa SA, Salciccioli J, Adams J, Salma P, Wysokinski W, McBane R, et al. A practical review of the emerging direct anticoagulants, Lab Monitoring, Reversal agents(Review). J Clin Med. 2018;7(2):29.

44. Moll S. The Haematologist ASH news and reports: Use of Direct Oral Anticoagulants in Patients on Haemodialysis. Washington: American Society of Hematology. 2017. Available from: https://www.hematology.org/ Thehematologist/Diffusion/7794.aspx

45. Staerk L, Gerds TA, Lip GYH, Ozenne B, Bonde AN, Lamberts M, et al. Standard and reduced doses of dabigatran, Rivaroxaban and Apixaban for stroke prevention in atrial fibrillation: A nationwide cohort study. J Intern Med. 2017;283(1):45-55.

46. Kokubo Y. New Oral Anticoagulants (NOAC) Studies in the Ideal and the Real World-Needs of Prospective Observational Studies. Circ J2015;79(5):962-3

47. Scaglione F. New oral anticoagulants: Comparative pharmacology with Vitamin K Antagonists. Clin Pharmacokinet. 2013;52(2):69-82.
48. Awesat J, Sagy I, Haviv YS, Rabinovich A, Jotkowitz A, Shleyfer E, et al. Dabigatran induced Nephropathy and its successful treatment with Idarcizumab: Case report and literature review. Thromb Res. 2018;169:120-2.

49. Esenberg SE, Kamphuisen PW, Sijpkens MK, Meijers JC, Buller HR, Levi M. Reversal of Rivaroxaban and Dabigatran by Prothrombin Complex Concentrate clinical Perspective: A randomised, placebo-control, crossover study in healthy subjects. Circulation. 2011;124(14):1573-9.

50. Rasitan NJ. Janseen submits supplemental new drug application to FDA seeking new indication for XARELTO (Rivaroxaban) for patients with chronic coronary and or peripheral arterial disease (CAD/PAD). Johnson and Johnson Innovation. 2017. Available from:https://www.jnj.com/media-center/pressreleases/janssen-submits-supplemental-new-drug-application-to-fda-seekingnew-indications-for-xarelto-rivaroxaban-for-patients-with-chronic-coronaryand-or-peripheral-artery-disease-cad-pad. 2017

51. Anand SS, Caron F, Yusuf S, Eikelboom JW, Bosch J, Dyal L, et al. Major adverse limb events in peripheral arterial disease: The COMPASS trial. J Am Coll Cardiol. 2018;71(20):2306-15.

52. Anand SS, Bosch J, Eikelboom JW, Connolly SJ, Diaz R, Widimsky P, et al. Rivaroxaban with or without aspirin in patients with stable peripheral or carotid artery disease: An international randomised, double blind placebo control trial. Lancet. 2018;391(10117):219-29.

53. Lameijer H, Aalberts JJJ, Veldhuisen DJV, Meijer K, Pieper PG. Efficacy and Safety of DOACs during pregnancy: A systematic Literature review. Thromb Res. 2018;169:123-7.

54. Mega JL, Braunwald E, Wiviott SD, Bassand JP, Bhatt DL, Bode C, et al. Rivaroxaban in patients with a recent acute coronary syndrome. N Engl J Med. 2012;366(1):09-19.

55. DrMandrolla J. Atrial Fibrillation, dabigatran/ rivaroxaban/ apixaban; A summary of rivaroxaban and Apixaban for the prevention of stroke in AF. 2011. Available from: http://www.drjohnm.org/2011/08let-there-be-three/ 2018

56. Noseworthy PA, Yao X, Abraham NS, Sangaralingham LR, McBane RD, Shah ND. Direct comparison of dabigatran, riovaroxaban and Apixaban for effectiveness and safety in non valvular atrial fibrillation. Chest. 2016;150(6):1300-12.

57. Chua D. Use of Non- Vitamin K antagoniat oral anticoagulants for stroke prevention in patients with Atrial fibrillation and underlying valvular heart disease: A systematic review. I Med Pub Journals. 2018;2(1):1-5.

58. Plitt A, Bansilal S. The Non vitamin K Antagonist Oral Anticoagulants and Atrial Fibrillation: Challenges and Considerations. J Atr Fibrillation. 2017;9(5):1547.

59. Clinical Trials.gov. USA: A Study of the Safety and Pharmacokinetics of Apixaban Versus Vitamin K Antagonist (VKA) or Low Molecular Weight Heparin (LMWH) in Paediatric Subjects with Congenital or Acquired Heart Disease Requiring Anticoagulation. 2019. Available from: https://clinicaltrials.gov/ct2/ show/NCT02981472\#wrapper. 2019

60. ClinicalTrials.gov. USA: Study to Evaluate a Single Dose of Apixaban in Paediatric Subjects at Risk for a Thrombotic Disorder. 2019. Available from: https://clinicaltrials.gov/ct2/show/NCT01707394. 2019

61. Weitz JI, Connolly SJ, Patel I, Salazar D, Rohatagi S, Mendell J, et al. Randomised parallel group, multicentre, multinational phase 2 study comparing Edoxaban, an oral Factor Xa inhibitors with warfarin for stroke prevention in patients with AF. Thromb Haemost. 2010;104(3):633-41.

62. Giugliano RP, Ruff CT, Braunwald E, Murphy SA, Wiviott SD, Halperin JL, et al. Edoxaban versus warfarin in patients with atrial fibrillation. $\mathrm{N}$ Engl $\mathrm{J}$ Med. 2013;369:2093-104.

63. Bohula EA, Giugliano RP, Ruff CT, Kuder JF, Murphy SA, Antman EM, et al. Impact of renal function on outcomes with edoxaban in the ENGAGE AF- TIMI 48 trial. Circulation. 2016;1(34):24-36.

64. Clinical Trials.gov. USA: Phase 1 Paediatric Pharmacokinetics/ Pharmacodynamics (PK/PD). Available from: https://clinicaltrials.gov/ct2/show/ NCT02303431. 2019

65. Evans S. FDA approves the first antidote for anticoagulants. 2018. http://www. drugdevelopment-technology.com. 2018

66. Pallandino M, Merli G, Thomson L. Evaluation of the oral direct factor $\mathrm{Xa}$ inhibitor-Betrixaban. Expert OpinInvestig Drugs. 2013;22(11):1465-72.

67. Chan NC, Bhagirath V, Eikelboom JW. Profile of Betrixaban and its potential in the prevention and treatment of venous thromboembolism. Vasc Health Risk Manag. 2015;11:343-51.

68. Ruff CT, Giugliano RP, Braunwald E, Hoffman EB, Deenadayalu N, Ezekowitz $M D$, et al. Comparison of the efficacy and safety of NOACs with Warfarin in 
patients with AF: A meta-analysis of randomised trials. Lancet. 2014;383:95562.

69. Sarich TC, Seltzer JH, Berkowitz SD, Costin J, Curnutte JT, Gibson CM, etal. Noval oral anticoagulants and reversal agents: Considerations for clinical development. Am Heart J. 2015;169(6):751-7.

70. Heo YA. Andexanet Alfa: First Global Approval. Drugs. 2018;78(10):1049-55.

71. Diagnostic and Interventional Cardiology. USA: FDA clears first reversal agent for rivaroxaban, apixaban anticoagulants. 2018. Available from: https://www. dicardiology.com/article/fda-clears-first-reversal-agent-rivaroxaban-apixabananticoagulants

72. FDA approval Betrixaban (BEVYXXA Portola) for the prophylaxis of VTE in adult patients. +US:FDA. 2017. Available from: https://www.accessdata.fda. gov/drugsatfda_docs/label/2017/208383s000lbl.pdf

73. Sardar P, Chatterjee S, Herzog E, Nairooz R, Mukherjee D, Halperin J. Noval oral anticoagulants in patients with renal insufficiency: A meta-analysis of Randomised trials. Can J Cardiol. 2014;30(8):888-97.

74. Vittorio P, Gentian D. Diagnostics and treatment of thrombotic Antiphospholipid syndrome (APS): A personal perspective. Thromb Res. 2018;169:35-40.
75. Czuprynska J, Patel JP, Arya R. Current challenges and future prospects in oral anticoagulant therapy. Br J Haematol. 2017;178(6):838-51.

76. Yao X, Abraham NS, Sangaralingham LR, Bellolio MF, McBane RD, Shah ND, et al. Effectiveness and safety of Dabigatran, Rivaroxaban and Apixaban versus Warfarin in non valvular atrial fibrillation. J Am Heart Assoc. 2016;5(6):13.

77. Pharmaceutical-technology.com. London: Anticoagulants drive market growth in multiple cardiovascular diseases. 2018. Available from: https://www. pharmaceutical-technology.com/comment/anticoagulants-drive-market-growthmultiple-cardiovascular-disease/

78. Newdrugapprovals.org. US: Idrabiotaparinux for anticoagulant therapy. 2014. Available from: https://newdrugapprovals.org/2014/02/08/idrabiotaparinux-foranticoagulant-therapy/

79. Summers RL, Sterling AS. Emergent Bleeding in Patients Receiving Direct Oral Anticoagulants. Air Med J. 2016;35(3):148-55.

80. Sanofi pulls Euroean and other regulatory filings for Mulsevo. 2012. www.the pharmaletter.com

81. Astellas Ditches Development of Oral Direct Factor Xa Inhibitor Darexaban. Genetic Engineering and Biotechnology News. 2011. 